Short communication

\title{
A study on the effect of the type and content of filler in epoxy-glass composite system on the friction and slide wear characteristics
}

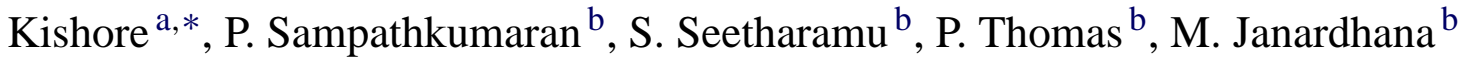 \\ a Department of Metallurgy, Indian Institute of Science, Center for Advanced studies, Bangalore 560 012, India \\ b Materials Technology Division, Central Power Research Institute, Bangalore 560 080, India
}

\begin{abstract}
The comparative performance of glass-epoxy (G-E) composites, having rubber in one instance and graphite of two differing levels in epoxy matrix resin in the other, during sliding in pin-on-disc type set up under varying load and sliding velocities is reported in this investigation. Besides conventional weighing, determination of coefficient of friction $(\mu)$ and examination of the worn surface features by scanning electron microscope (SEM) were undertaken to have an overall picture of the tribological behaviour of the filled composites.

For increased load and sliding velocity situations, higher wear loss was recorded. In case of rubber-bearing samples, the coefficient of friction values show an increasing trend with a rise in load and a decrease in their values for increase in velocity. The coefficient of friction increases with increase in load for a fixed velocity in higher graphite bearing samples. However, G-E composite having either lower or higher amount of graphite shows, respectively, either a decrease or increase in coefficient of friction with an increase in sliding velocity for a fixed load. Thus, the higher graphite bearing G-E composite records lower coefficient of friction for any combination of load and velocity. These are explained on the basis of frictional drag forces and formation of graphite film on the surface. Some of these deductions are supplemented by SEM observations.
\end{abstract}

Keywords: Glass-epoxy; Sliding wear; Coefficient of friction; SEM; Fillers; Rubber; Graphite

\section{Introduction}

Polymers and their composites are emerging as viable alternative products to metal-based ones in many common and advanced engineering applications [1]. The ease of fabrication, the availability of a good choice of materials from both thermoplastic and thermoset varieties and economic viability have made the advent of these newer materials for industries ranging from automobile to sports goods [2]. The many uses of these materials in space and aeronautical industry-related applications are well known [3].

However, to make these emerging materials even more attractive for use as components combating wear, it is imperative to first characterize the already large list of polymeric materials available for their tribological behavior and more

\footnotetext{
* Corresponding author. Tel.: +91 80 22932683; fax: +91 8023600472.

E-mail address: balkis@met.iisc.ernet.in ( Kishore).
}

importantly explore the possibilities of developing simpler and newer material systems which have attractive friction and wear resistant properties [4] besides load carrying capabilities. Towards this end, the development of filler-based polymer materials is engaging the attention of many research workers. Although the load sustaining abilities of thermosets are far more impressive compared to thermoplastics, for many a situation a still higher strength bearing polymeric materials are required. Fiber-reinforced polymers (FRP's) hence are an attractive system to examine. To make these fibrous systems tribologically even more viable, the possibilities of developing filled FRP's need to be thoroughly examined.

Organic [5] and inorganic [6] filler systems may be thought of. As such, rubber-bearing thermosets and graphite-bearing epoxies [7] are candidate materials for venturing into FRP's containing such fillers as a result of attractive impact and tribological properties, respectively. This effort is, hence, an attempt to bridge this information gap existing between the 
inclusion of fillers and the tribological properties that accrue, as graphites are known to be good solid lubricants. Hence in the present work, two different levels of graphitebearing glass-epoxy (G-E) systems were compared, first between themselves and then with an elastomer containing one. Besides the conventional methods followed in wear experiments, like noting weight changes and coefficient of friction measurements, the present work looks at the worn surface features using advanced tools like scanning electron microscope (SEM).

\section{Experimental}

\subsection{Materials and processes}

A hand lay up procedure was adopted for making rubberbearing and graphite-containing G-E composites. The reinforcement material used was a 7-mil E-glass plain-woven fabric with epoxy compatible finish. LY 556 epoxy was used as the resin for the matrix material with HY 951 grade room temperature curing hardener and diluent DY 021 (both supplied by Hindustan Ciba Geigy). The lay up procedure consisted of placing a glass surface mat to give smooth surface finish to the top and bottom layers of the cured composite, over which, the first of the bi-directional E-glass epoxy compatible finish bearing fabric was placed. On this, a resin hardener mix prepared for this purpose was smeared. Over this, another layer of the fabric was laid down and the resin was spread once again. The process was repeated till all the 17 fabrics (arrived at by trial experiments) made ready for the lay up, were used up in the stacking arrangement. Use of spacers of about $3 \mathrm{~mm}$ thickness helped in obtaining laminates of the required thickness following final curing. This general procedure was used for making rubber and graphite-bearing G-E laminates. However, for obtaining the rubber-filled laminates, a 3 wt.\% hydroxyl-terminated poly (butadiene-co-acrylonitrile), i.e. HTBN rubber was added. To make the graphite-bearing G-E laminate, a -300 mesh, 99.99 purity, graphite powder mixed into a weighed quantity of the resin was smeared on to two chosen layers (i.e. after 5th and at 10th glass fabric layer) while making the lay up. In one set of samples; about $2.5 \mathrm{wt}$.\% of graphite powder in resin was introduced, while in the second set, roughly $4.5 \mathrm{wt} . \%$ was included. Both the rubber and graphite-bearing laminates were made by pressing the lay up in a compression unit operated at about $0.4 \mathrm{MPa}$ to yield about $3 \mathrm{~mm}$ thick laminates. The curing was carried out at ambient conditions for a minimum period of $24 \mathrm{~h}$. The rubber-bearing laminate is designated 'A', the lower of the two graphite-bearing laminate (i.e. $2.5 \mathrm{wt} . \%$ ) is denoted by ' $\mathrm{B}$ ' and the $4.5 \mathrm{wt} . \%$ graphite-bearing is designated ' $C$ ' for purposes of discussion of the results (Table 1). Wear test coupons of geometry $6 \mathrm{~mm} \times 6 \mathrm{~mm} \times 3 \mathrm{~mm}$ were cut from the laminates using a diamond tipped cutter and then tested for characterizing the friction and wear properties.
Table 1

Details of samples regarding the matrix, reinforcement material, additive and wt.\%

\begin{tabular}{lllll}
\hline Sample & Matrix & $\begin{array}{l}\text { Reinforcement } \\
\text { material }\end{array}$ & Additive & wt.\% \\
\hline A & Epoxy & E-glass fabric & HTBN rubber & 3 \\
B & Epoxy & E-glass fabric & Graphite powder & 2.5 \\
C & Epoxy & E-glass fabric & Graphite powder & 4.5 \\
\hline
\end{tabular}

\subsection{Wear tests: set up and test parameters}

The test set up used in this investigation is the widely used pin-on-disc machine. A G-E composite sample is fixed to a grooved pin sample using a suitable adhesive to form a pin assembly (as indicated in Fig. 1). This way the mounted $\mathrm{G}-\mathrm{E}$ sample is made to come in contact with a rotating hardened (HRC 62 with surface finish $10 \mu \mathrm{m}$ ) alloy steel disc counter surface. The sample is dead weight loaded (normal load) through a string to which pan assembly is attached [8]. A $20 \mathrm{~kg}$ load cell is fixed tangential to the lever arm through which frictional load is measured. The output of the load cell is connected to a strip chart recorder to measure the frictional load. The coefficient of friction is calculated, by dividing the steady state frictional load by the normal load applied to the specimen. The mounting arrangement of the G-E sample is made in such a way that the thickness side of the laminate containing the lay up consisting of fibrous glass and epoxy resin system is made to come in contact with the disc (as indicated in the inset of Fig. 1). The initial weight of the pin assembly is measured in each test using a sensitive electronic
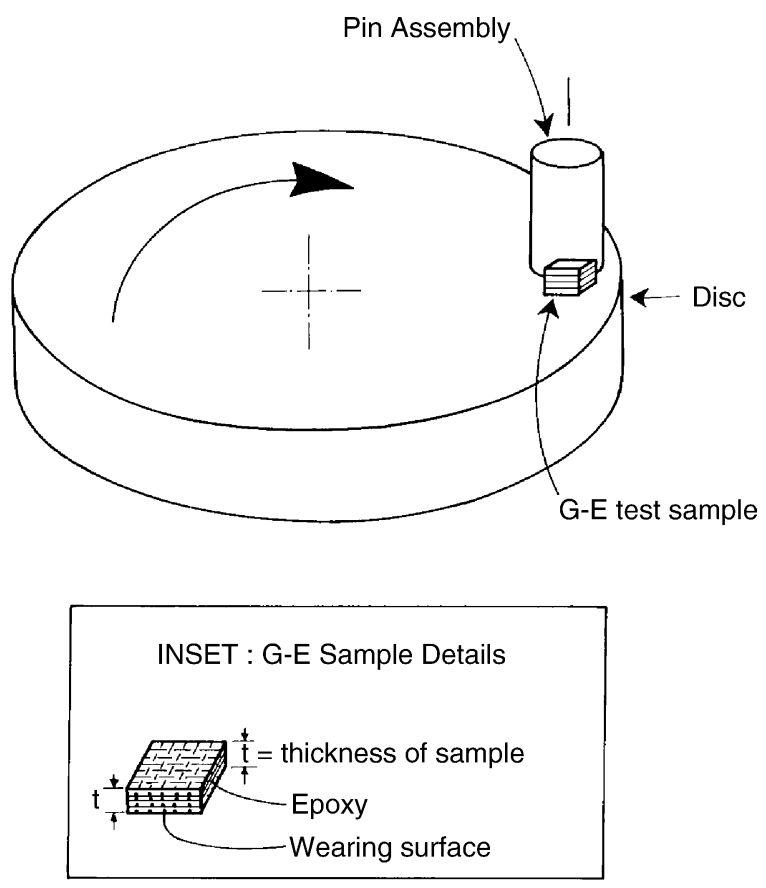

Fig. 1. Pin assembly showing location of the G-E test sample (inset: glass fabric details along with epoxy resin matrix showing the sample surface subjected to wear). 
digital weighing balance. The tests are carried out by selecting the test parameters viz., normal load, velocity and sliding distance. Following the completion of the test, the pin assembly is weighed accurately again using the same balance. Thus, the weight changes, due to wear runs of the specimen, were recorded and are reported here in.

The sliding distance was maintained at $5 \mathrm{~km}$ for both the rubber and graphite-bearing samples. A load and velocity ranges of $29-69 \mathrm{~N}$ and $2-5 \mathrm{~m} / \mathrm{s}$, respectively, were chosen. The weight loss of the sample was determined by noting the difference in the initial and final weight readings of the sample. Four samples were run for each combination of the test parameters employed. The results reported are thus the average of four readings and the scatter band in the experiments is plotted for each of the velocity and load employed in this investigation.

\subsection{SEM examinations}

For SEM examinations, the samples were coated with a thin layer of gold using a sputtering unit. Both the surface features and information about wear of the counter surface could not be undertaken due to experimental constraints.

\section{Results and discussion}

\subsection{Wear measurements}

Fig. 2 shows the details of the weight loss with respect to sliding velocity for the rubber-containing A type samples for different loads. The data show that weight loss increases with either increase in load or sliding velocity. Similar results are obtained for both B (Fig. 3) and C (Fig. 4) samples. To show the relative wear loss for differing loads and sliding velocities, the results are now represented in the form of bar diagram in Fig. 5(a)-(d) for a constant load ( $29 \mathrm{~N})$ and sliding distance $(5 \mathrm{~km})$ but varying in sliding velocity. Similarly, Fig. 6(a)-(d) and Fig. 7(a)-(d) show the corresponding situations obtained at higher loads (i.e. 49 and $69 \mathrm{~N}$, respectively). From such bar plots, it is noted that of the three filler bearing varieties

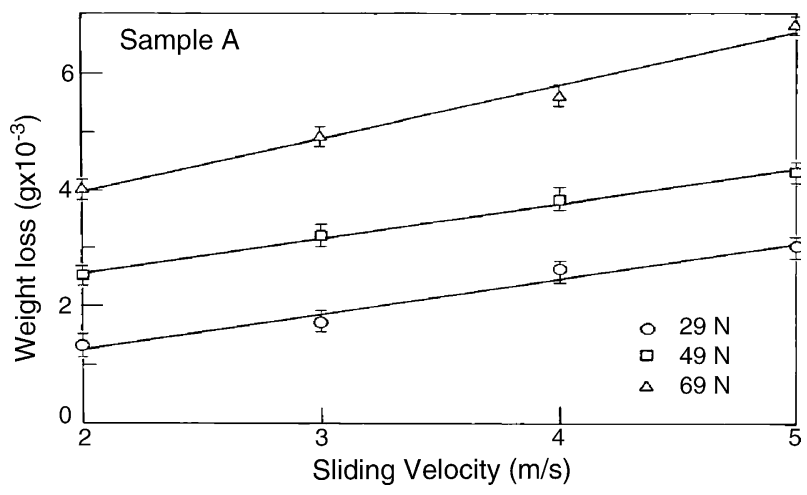

Fig. 2. Weight loss vs. sliding velocity for different loads in A type samples.

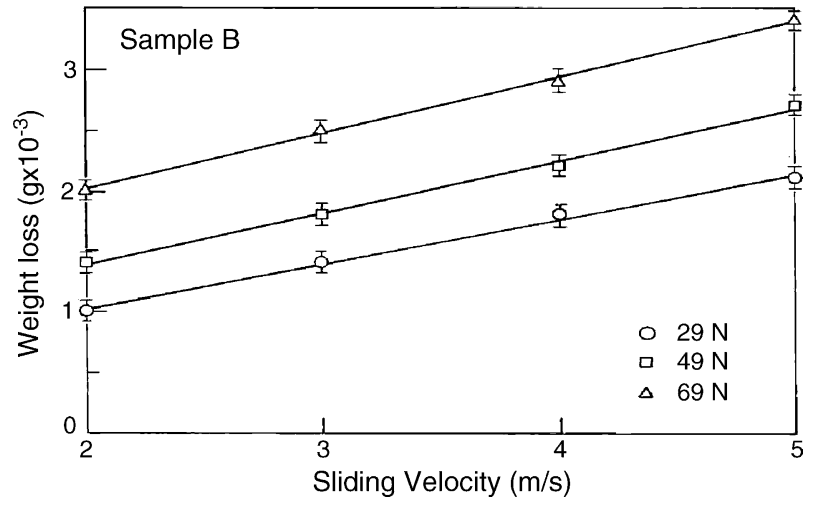

Fig. 3. Weight loss vs. sliding velocity for different loads in B type samples.

tested, the $\mathrm{C}$ type exhibits the least wear and A variety the maximum for all conditions.

\subsection{Coefficient of friction}

Differing trends in the coefficient of friction measurements are observed (Table 2). For sample A with an increase in the sliding velocity, the coefficient of friction $(\mu)$ increases, where as with increase in load under constant sliding velocity, $\mu$ decreases, thus highlighting the significance of the test parameters on $\mu$ values for rubber-bearing samples.

For C type samples, like in A, an increasing trend in $\mu$ is recorded for sliding velocities increasing in the range $2-5 \mathrm{~m} / \mathrm{s}$ for a constant load. But unlike samples A, a increase in load under constant velocity increases $\mu$, slightly.

For B samples, a stepwise increase in load under constant sliding velocity results in an increase followed by decrease of $\mu$. But for increased sliding velocities under constant load, a different trend in the form of decrease in values, compared to $\mathrm{C}$ type, is seen for $\mathrm{B}$ type sample.

\subsection{Scanning electron microscopy}

The SEM observation on a A type shows (Fig. 8) debris formation and broken fibers at $69 \mathrm{~N}$ and $2 \mathrm{~m} / \mathrm{s}$ sliding conditions. Keeping the load constant, but increasing the slid-

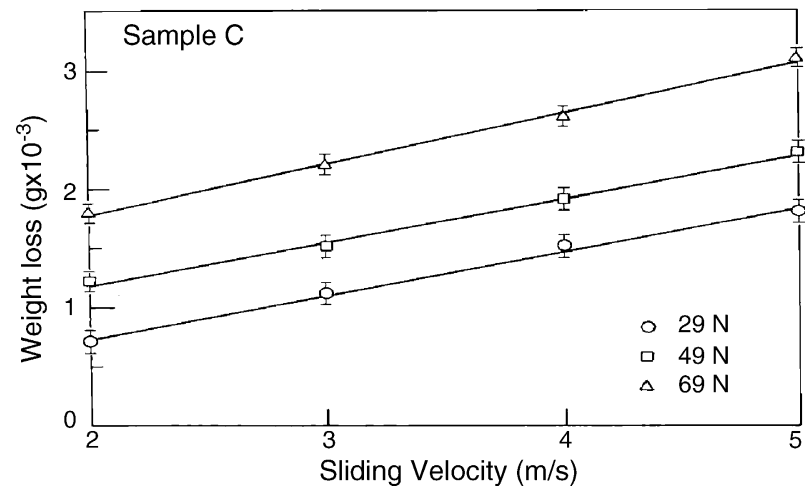

Fig. 4. Weight loss vs. sliding velocity for different loads in C type samples. 

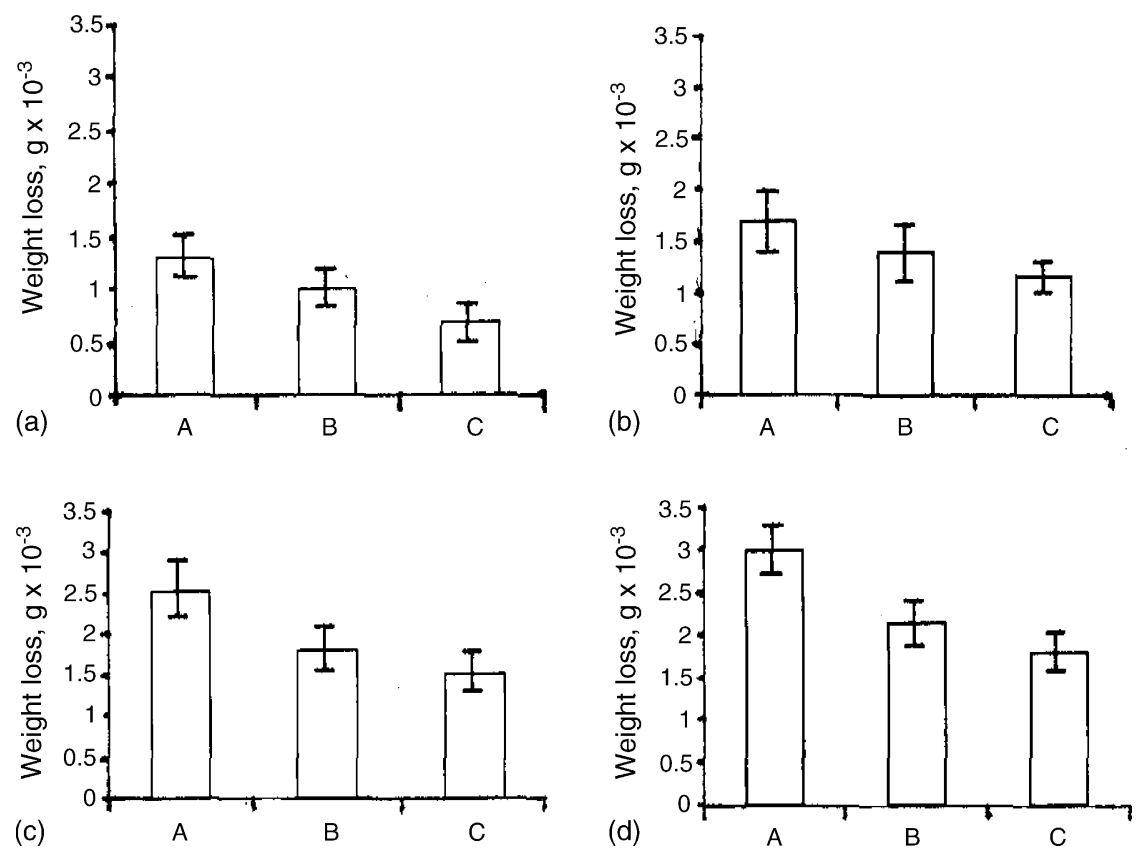

Fig. 5. (a) Wear data of A-C samples at $29 \mathrm{~N}$ load application for sliding velocity of $2 \mathrm{~m} / \mathrm{s}$; (b) wear data of A-C samples at $29 \mathrm{~N}$ load application for sliding velocity of $3 \mathrm{~m} / \mathrm{s}$; (c) wear data of A-C samples at $29 \mathrm{~N}$ load application for sliding velocity of $4 \mathrm{~m} / \mathrm{s}$; (d) wear data of A-C samples at $29 \mathrm{~N}$ load application for sliding velocity of $5 \mathrm{~m} / \mathrm{s}$.
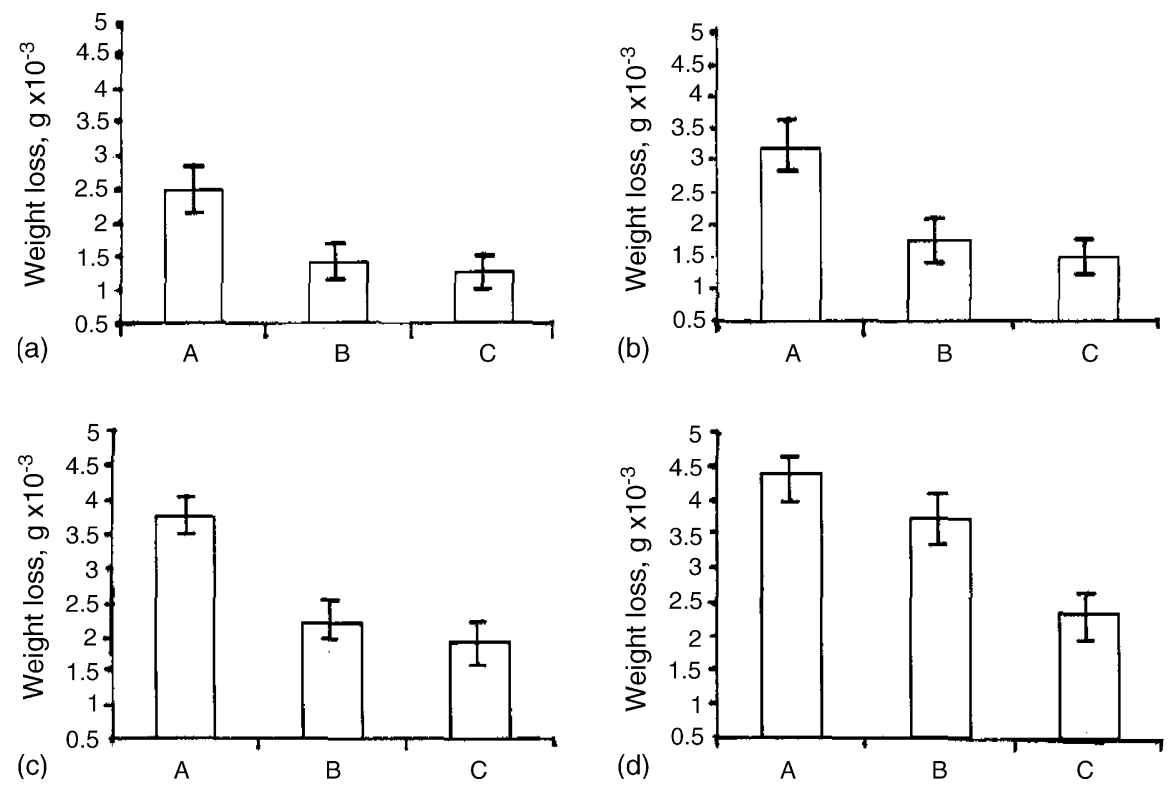

Fig. 6. (a) Wear data of A-C samples at $49 \mathrm{~N}$ load application for sliding velocity of $2 \mathrm{~m} / \mathrm{s}$; (b) wear data of A-C samples at $49 \mathrm{~N}$ load application for sliding velocity of $3 \mathrm{~m} / \mathrm{s}$; (c) wear data of A-C samples at $49 \mathrm{~N}$ load application for sliding velocity of $4 \mathrm{~m} / \mathrm{s}$; (d) wear data of A-C samples at $49 \mathrm{~N}$ load application for sliding velocity of $5 \mathrm{~m} / \mathrm{s}$.

Table 2

Coefficient of friction in A-C type G-E samples under all experimental conditions

\begin{tabular}{|c|c|c|c|c|c|c|c|c|c|c|c|c|}
\hline \multirow[t]{3}{*}{ Load (N) } & \multicolumn{12}{|c|}{ Coefficient of friction $(\mu)$} \\
\hline & \multicolumn{3}{|c|}{ Sliding velocity $2 \mathrm{~m} / \mathrm{s}$} & \multicolumn{3}{|c|}{ Sliding velocity $3 \mathrm{~m} / \mathrm{s}$} & \multicolumn{3}{|c|}{ Sliding velocity $4 \mathrm{~m} / \mathrm{s}$} & \multicolumn{3}{|c|}{ Sliding velocity $5 \mathrm{~m} / \mathrm{s}$} \\
\hline & A & B & $\mathrm{C}$ & A & B & $\mathrm{C}$ & A & B & $\mathrm{C}$ & A & B & $\mathrm{C}$ \\
\hline 29 & 0.70 & 0.41 & 0.21 & 0.75 & 0.40 & 0.23 & 0.79 & 0.39 & 0.25 & 0.85 & 0.37 & 0.30 \\
\hline 49 & 0.61 & 0.45 & 0.23 & 0.65 & 0.43 & 0.25 & 0.71 & 0.42 & 0.28 & 0.82 & 0.41 & 0.31 \\
\hline 69 & 0.49 & 0.44 & 0.24 & 0.57 & 0.42 & 0.27 & 0.61 & 0.41 & 0.29 & 0.63 & 0.39 & 0.32 \\
\hline
\end{tabular}



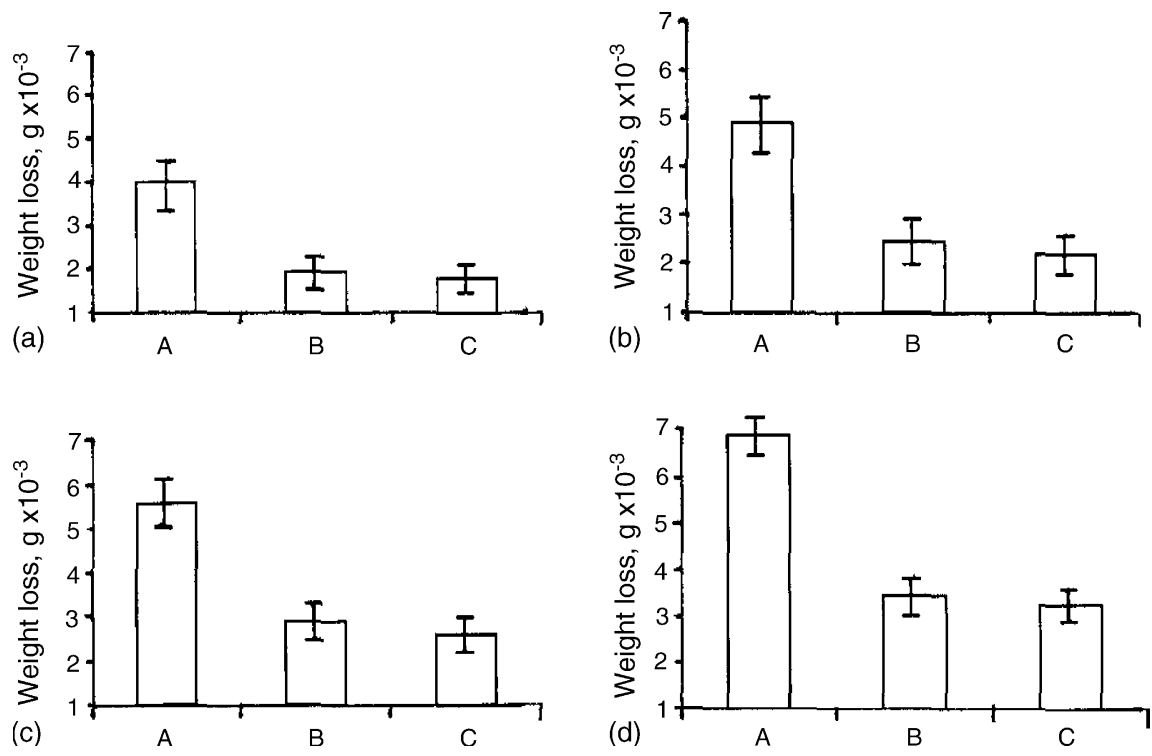

Fig. 7. (a) Wear data of A-C samples at $69 \mathrm{~N}$ load application for sliding velocity of $2 \mathrm{~m} / \mathrm{s}$; (b) wear data of A-C samples at $69 \mathrm{~N}$ load application for sliding velocity of $3 \mathrm{~m} / \mathrm{s}$; (c) wear data of A-C samples at $69 \mathrm{~N}$ load application for sliding velocity of $4 \mathrm{~m} / \mathrm{s}$; (d) wear data of A-C samples at $69 \mathrm{~N}$ load application for sliding velocity of $5 \mathrm{~m} / \mathrm{s}$.

ing velocity leads to appearance of smaller-sized fibers with matrix debris well spread out (Fig. 9). Keeping the sliding velocity constant, but decreasing the load to $29 \mathrm{~N}$ yields a sample with good spread of the matrix, cracks in the matrix and fewer debris (Fig. 10). A rise in the velocity $(5 \mathrm{~m} / \mathrm{s})$ at this load results in greater wear of the matrix and exposure of the fibers (Fig. 11).

B type samples, on the other hand, show lesser spread of the matrix debris (Fig. 12) and longer fibers compared to A type (Fig. 8) under $69 \mathrm{~N}$ load and $2 \mathrm{~m} / \mathrm{s}$ sliding velocity. Fig. $13(69 \mathrm{~N}$ and $5 \mathrm{~m} / \mathrm{s})$ displays large fibers similar to fibers seen in the B type sample subjected to a lower sliding velocity of $2 \mathrm{~m} / \mathrm{s}$ (Fig. 12). The length of these fibers appear longer compared to the fibers observed for samples A under corresponding test conditions (Fig. 9). Lowering of load and velocity in $B$ type yields surfaces which show a less smear-

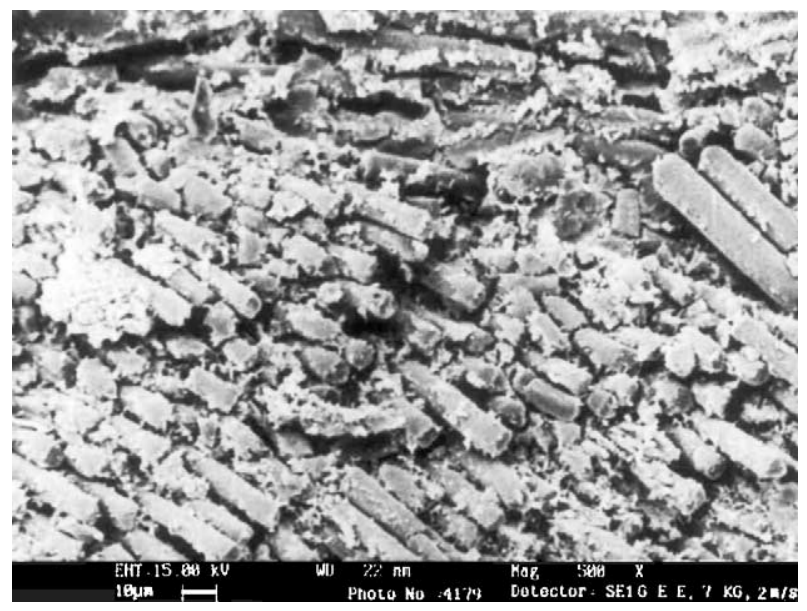

Fig. 8. SEM picture of A sample at $69 \mathrm{~N}$ load and $2 \mathrm{~m} / \mathrm{s}$ velocity featuring numerous fibers some of which are fragmented. ing wear of the matrix region (Fig. 14) compared to A type samples (Fig. 10). Also, the matrix has a tendency to show dark-coloured matrix zones at the higher velocities (Fig. 15) compared to the lower velocities (Fig. 14). The colouration change in type B samples, not noticed in type A samples point to the origin in the difference in the material tribological behaviour i.e., sliding wear and coefficient of friction characteristics.

Type $\mathrm{C}$ samples also show spreading of the matrix with exposed long fibers (Fig. 16). Even with a rise in velocity, long fibers are retained despite some tendencies to fragment (Fig. 17). Darkening of the resin, a feature seen for type B samples, is noticed in some areas (for example, in the lower right region of Fig. 16). Also comparing $\mathrm{B}$ and $\mathrm{C}$, the extent of wear is less in the latter, which is supported by the features on the surface of sample, where lesser-delaminated worn conditions are noticed (Fig. 16).

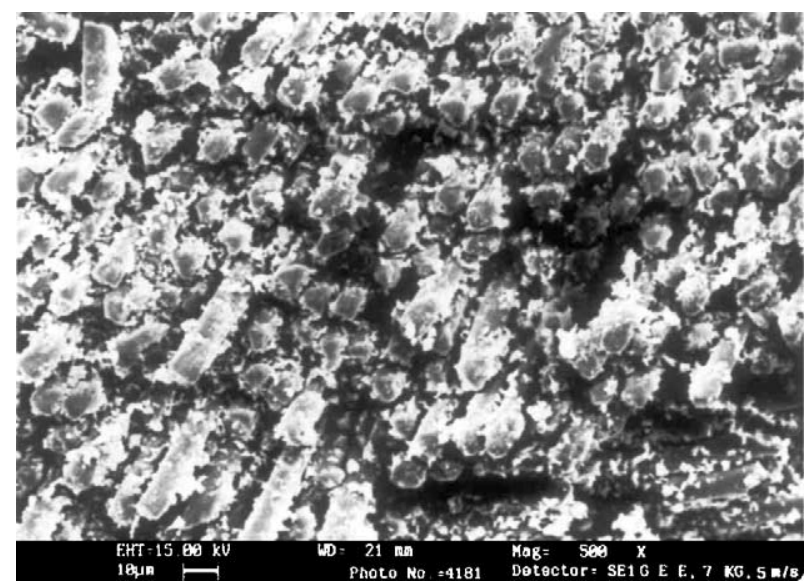

Fig. 9. The effect of higher velocity $(5 \mathrm{~m} / \mathrm{s})$ on A sample showing well spread out of the matrix debris at $69 \mathrm{~N}$ load. 


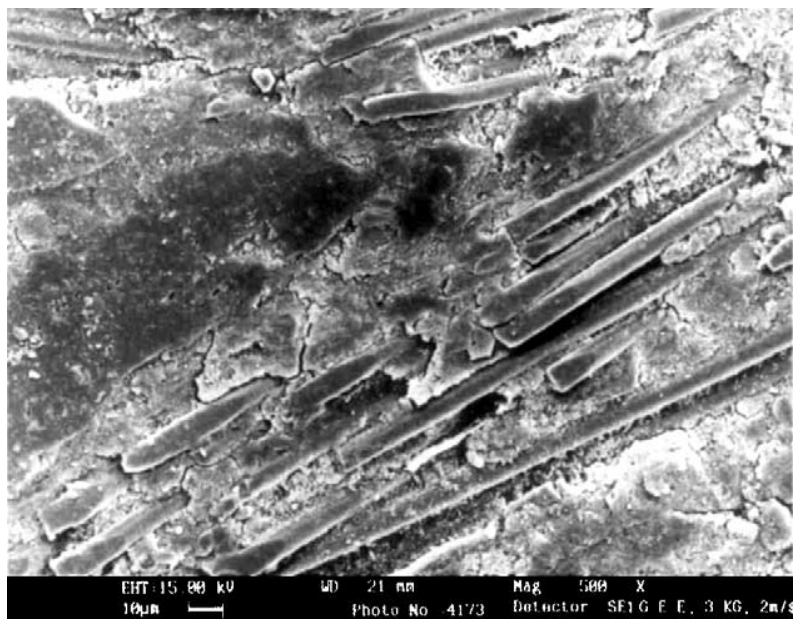

Fig. 10. SEM photograph in sample A for lower load (29N) application at $2 \mathrm{~m} / \mathrm{s}$ velocity displaying wider spread of the matrix, but fewer debris and cracks.

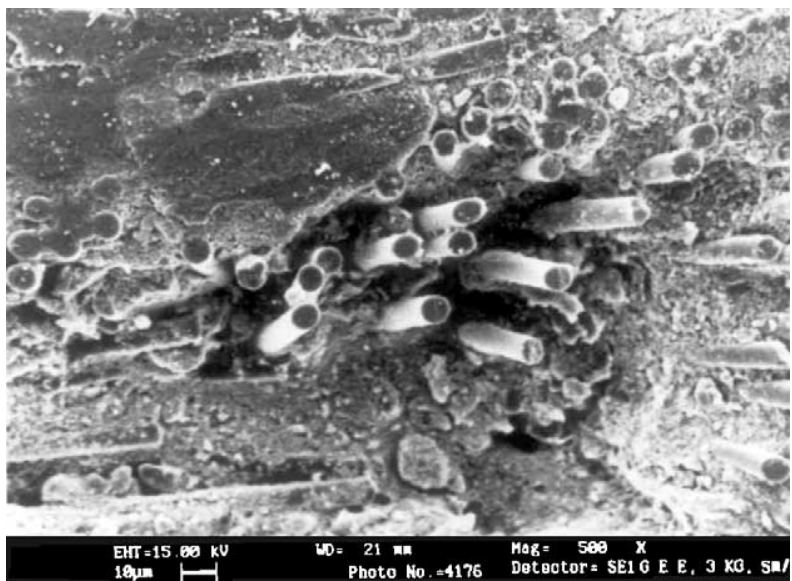

Fig. 11. The effect of increased velocity $(5 \mathrm{~m} / \mathrm{s})$ for the A type sample bringing out increased exposure of the fibers by keeping the load at $29 \mathrm{~N}$.

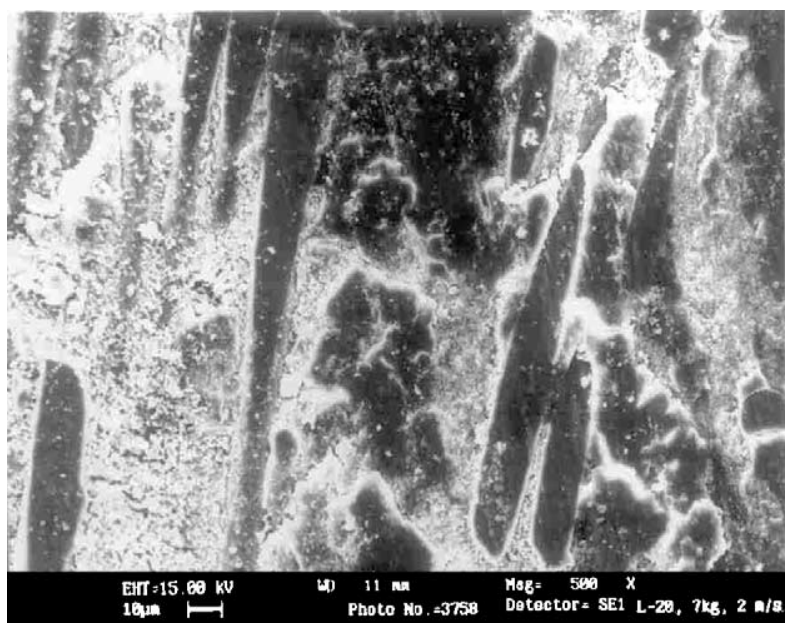

Fig. 12. B type sample for high load $(69 \mathrm{~N})$ and low velocity $(2 \mathrm{~m} / \mathrm{s})$ situation detailed a lesser spread of the matrix debris and retention of longer fibers compared to that seen in A type of sample shown in Fig. 8.

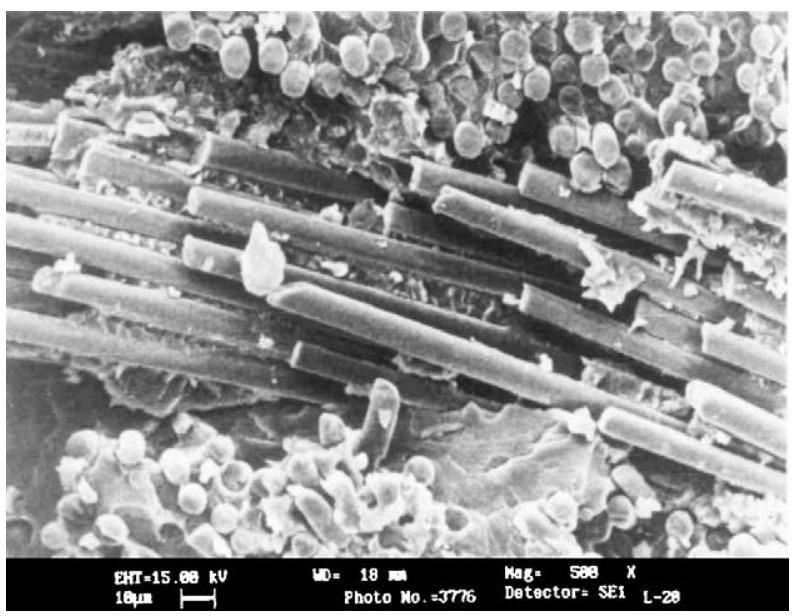

Fig. 13. The influence of higher velocity $(5 \mathrm{~m} / \mathrm{s})$ on B sample at $69 \mathrm{~N}$ load application showing breakage of long fibers.

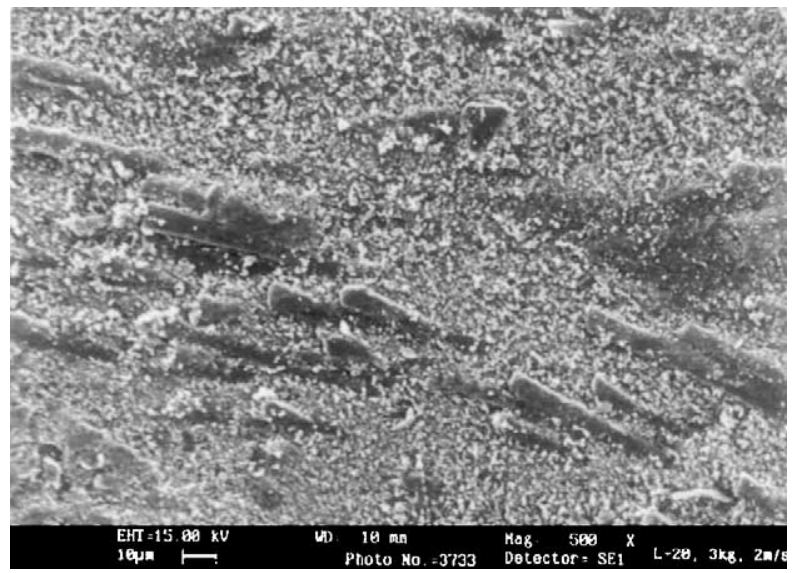

Fig. 14. The effect of decreased load $(29 \mathrm{~N})$ and lower velocity $(2 \mathrm{~m} / \mathrm{s})$ showing wear out of the matrix region and masking of fibers in the B type of sample.

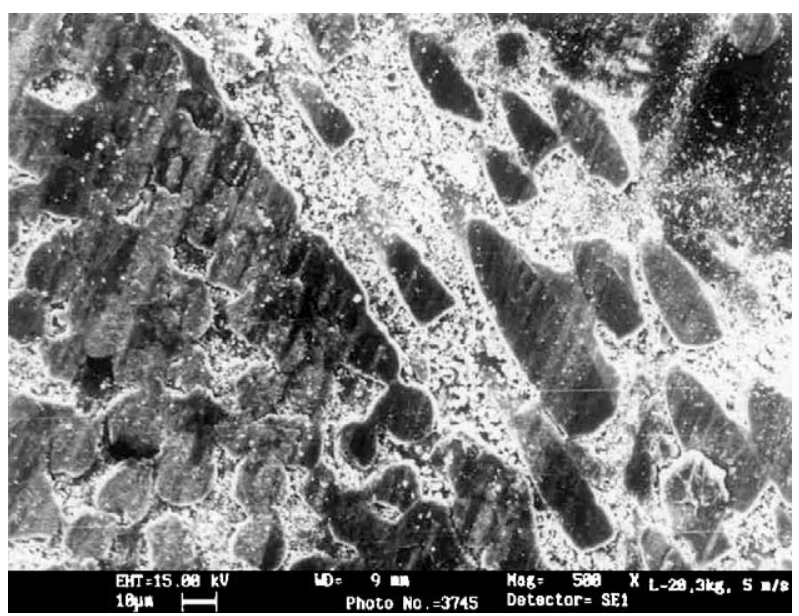

Fig. 15. The SEM observations at $29 \mathrm{~N}$ load highlighting darkened matrix zones and matrix debris in B type sample subjected to higher velocity $(5 \mathrm{~m} / \mathrm{s})$. 


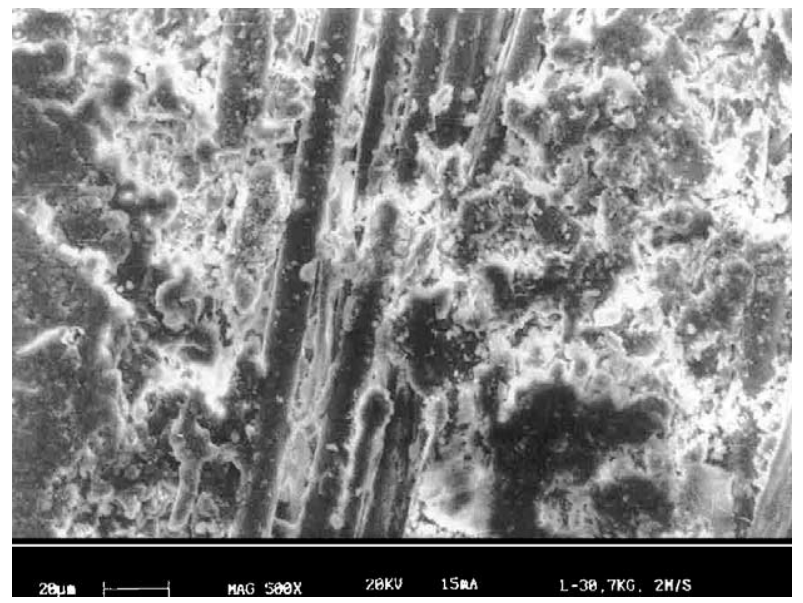

Fig. 16. C type sample exhibiting spread of the matrix on lengthy fibers despite the use of higher load $(69 \mathrm{~N})$ and lower velocity $(2 \mathrm{~m} / \mathrm{s})$.

As for the high load $(69 \mathrm{~N})$ and high speed $(5 \mathrm{~m} / \mathrm{s})$, it is seen that the A type sample shows broken fibers and greater debris (Fig. 9) than the B type sample (Fig. 13), while the debris and the length of the fragmented fibers are least for the $\mathrm{C}$ type sample (Fig. 17). Also noticed are hardly any breakages of fiber with very less matrix wear in addition to network of very small cracks at $29 \mathrm{~N}$ load and $2 \mathrm{~m} / \mathrm{s}$ sliding velocity for $\mathrm{C}$ type samples (Fig. 18). Increasing the sliding velocity to $5 \mathrm{~m} / \mathrm{s}$ and keeping the load constant for $\mathrm{C}$ type samples results in masking of fibers by the matrix together with debris formation (Fig. 19). These observations are consistent with the experimental weight loss data presented earlier. A decreasing wear loss with increasing amounts of graphite in epoxy-glass system, as earlier been reported [7] and thus the present results on graphite in epoxy-glass system corroborates the previous findings [7].

To explain the reduced wear in B type than in A type samples, the abilities of graphite to form a film (lubricant) layer and reduce frictional drag forces can be invoked. In-

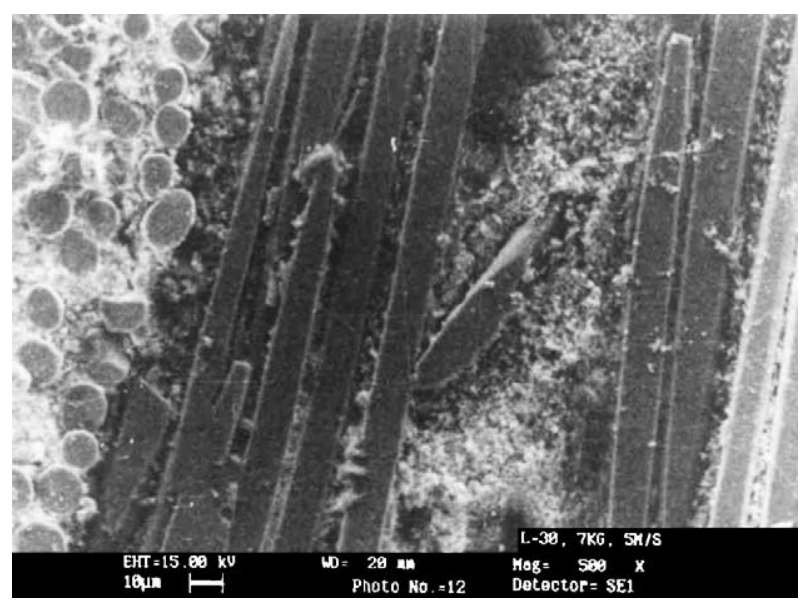

Fig. 17. C type sample showing features of $69 \mathrm{~N}$ load subjected to higher sliding velocity $(5 \mathrm{~m} / \mathrm{s})$ displaying least matrix debris formation and some fiber fragmentation tendencies.

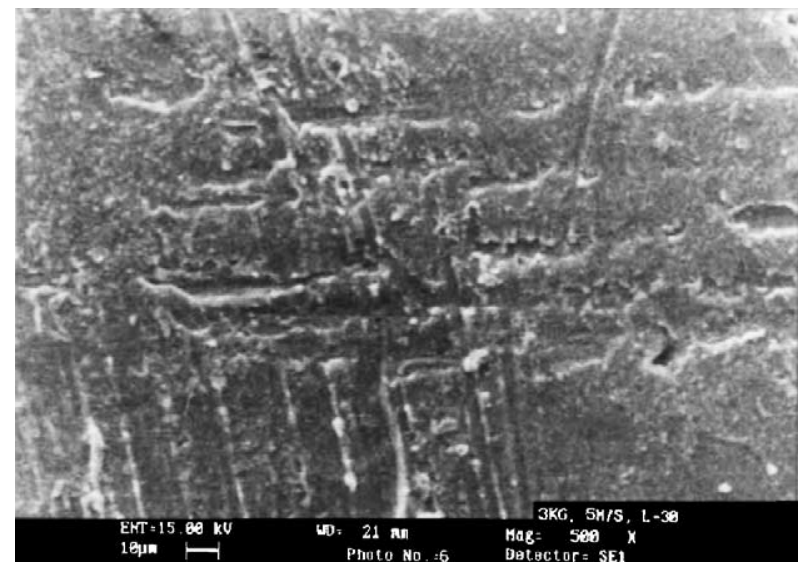

Fig. 18. The influence of very low velocity $(2 \mathrm{~m} / \mathrm{s})$ and load ( $29 \mathrm{~N})$ in C type sample showing small cracks forming a kind of network.

deed, graphites with the basal plane shear are known to be good solid lubricants. Graphite forms a film, which has an effect to reduce wear as seen in type B. This argument gets further support when the data obtained for type $\mathrm{C}$ samples are also considered. The $\mathrm{C}$ type samples containing higher amounts of graphite of two layers has a lower coefficient of friction (Table 2) as well as lower wear loss values (Fig. 4). The greater ease of film formation assists in lubricating the contact surface and causing less wear of the material. This argument is supported by lower $\mu$ obtained for $\mathrm{C}$ type compared to B type samples. Similar results were previously reported in a epoxy-graphite system exhibiting a lower wear loss with increased graphite content [7]. The change in the pattern of friction with either sliding velocity or load, seen for graphite-bearing (i.e. for $\mathrm{B}$ and $\mathrm{C}$ types), being different compared to rubber-bearing (A) can be ascribed to the frictional heat [9] and attendant property changes in graphite and to the optimum level of graphite film thickness above which the film layer formed may have differing response to the operating conditions. In the present study, for the velocity

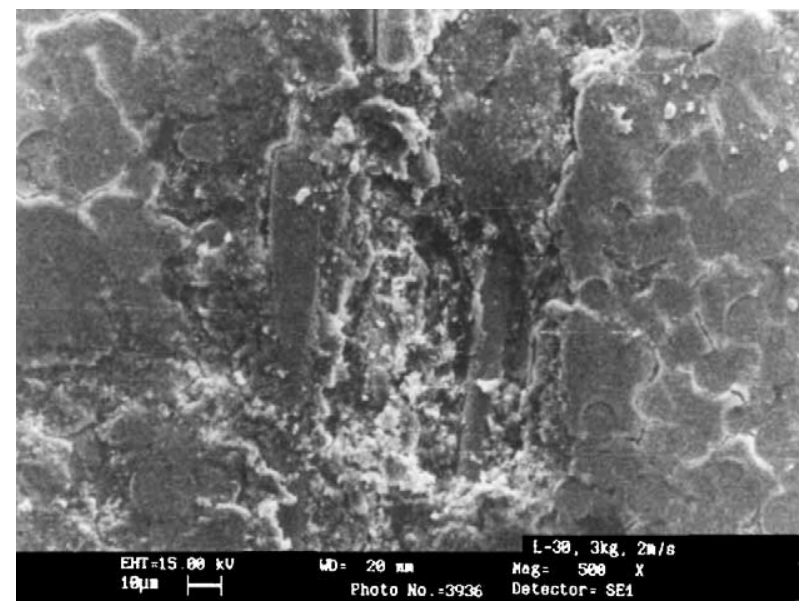

Fig. 19. SEM micrograph details the features in the $C$ type sample subjected to $29 \mathrm{~N}$ load and $5 \mathrm{~m} / \mathrm{s}$ sliding velocity, wherein masking of the fibers by the debris is noticed. 
range $2-5 \mathrm{~m} / \mathrm{s}$, the $\mu$ values increased steadily with load and after reaching a peak, the value decreased for the B type sample. Incidentally, it was noticed that removal of debris formed during experiments contributed to increased values of $\mu$, thus supporting the contention that thickness of already formed graphite layer during the build up and its retention on the surface during continuous contact with the steel counterface has an important effect on the friction and wear performance of the $\mathrm{G}-\mathrm{E}$ composite systems.

\section{Conclusions}

The response to tribo situations in G-E polymer composite system is dependent on filler type as well as its amount. Between the two fillers attempted in this work, graphite-bearing ones exhibit lower wear loss, whose value drops down further when the content of the filler in the composite is raised.

As regards the coefficient of friction, no one common trend could be observed. This is partly due to the response of the fillers being different. The rubber-bearing samples being elastic offer a different tribo situation compared to graphites, which are prone to basal slip. The amount of this material on the tribo surface also has a bearing on the test parameters recorded. The work points to the need to employ a hybridfilled G-E system, where the differing responses arising from rubber and graphite could well be tapped for applications requiring low wear loss accompanied by moderate values of friction.

\section{Acknowledgements}

The authors would like to acknowledge the assistance of Sri D. Mollaiah and Sri. A.V. Narayan of IISc for the help rendered and the Chairman of the Department of Metallurgy, IISc for the keen interest shown in the work. The authors thank the Director General and the management of CPRI for the permission extended to publish this paper. The authors also thank Sri. S. Vynatheya and Sri. R.K. Kumar for the help rendered in taking SEM photographs and conducting experiments. The help rendered by T.R. Raghu kiran and Santosh V. Angadi in preparing the text is acknowledged with thanks.

\section{References}

[1] ASM Handbook, ASM International, Materials Park, USA, 18, 1992.

[2] O.P. Bahl, Paper presented at International Union of Material Research Societies-International Conference in Asia (IUMRS-ICA 98), October 13-16, Bangalore, India, 1998.

[3] J.A. Baille, Woven fabric in aerospace structures, in: Handbook of Composites, vol. 2, North-Holland, Amsterdam, 1989, p. 353.

[4] S.K. Biswas, K. Vijayan, Wear 158 (1992) 193.

[5] S. Kaushal, Kishore, J. Mater. Sci. Lett. 11 (1992) 86.

[6] Kishore, K. Kumar, High Temp. Mater. Process. 17 (4) (1998) 271.

[7] C. Subramannian, P. Asaithambi, Kishore, J. Reinf. Plast. Compos. 5 (1986) 200

[8] P. Sampathkumaran, S. Seetharamu, A. Murali, R.K. Kumar, Kishore, Bull. Mater. Sci. 21 (4) (1998) 335

[9] V. Bankaruswamy, Kishore, Wear 86 (1993) 173. 